\title{
Adsorption of Methyl Violet Dye From Wastewater Using Poly(Methacrylic Acid-co- acrylamide)/bentonite Nanocomposite Hydrogels
}

\section{Hamid Safarzadeh}

University of Tehran College of Engineering

\section{Seyed Hamed Mousavi}

University of Tehran College of Engineering

Seyed Jamaleddin Peighambardoust ( $\nabla_{\text {j.peighambardoust@tabrizu.ac.ir ) }}$

University of Tabriz

\section{Reza Mohammadi}

University of Tabriz

Seyed Hadi Peighambardoust

University of Tabriz Faculty of Agriculture

\section{Research Article}

Keywords: Methacrylic acid-co-acrylamide copolymer, Nanocomposite hydrogel, Adsorption, Methyl Violet

Posted Date: July 20th, 2021

DOl: https://doi.org/10.21203/rs.3.rs-700381/v1

License: (c) (i) This work is licensed under a Creative Commons Attribution 4.0 International License.

Read Full License

Version of Record: A version of this preprint was published at Journal of Polymer Research on March 8th, 2022. See the published version at https://doi.org/10.1007/s10965-022-02956-0. 


\title{
Adsorption of methyl violet dye from wastewater using poly(methacrylic acid-co-acrylamide)/bentonite nanocomposite hydrogels
}

\author{
Hamid Safarzadeh ${ }^{1}$, Seyed Hamed Mousavi ${ }^{1 *}$, Seyed Jamaleddin Peighambardoust ${ }^{2 * *}$, Reza Mohammadi ${ }^{3}$, Seyed \\ Hadi Peighambardoust ${ }^{4}$ \\ ${ }^{1}$ Separation Processes \& Nanotechnology Lab, Faculty of Caspian, College of Engineering, University of Tehran, \\ Tehran, Iran \\ ${ }^{2}$ Faculty of Chemical and Petroleum Engineering, University of Tabriz, Tabriz, 5166616471, Iran, \\ ${ }^{3}$ Polymer Research Laboratory, Faculty of Chemistry, University of Tabriz, Tabriz, Iran \\ ${ }^{4}$ Department of Food Science, College of Agriculture, University of Tabriz, Tabriz 5166616471, Iran \\ *Corresponding author email: mhmousavi@ut.ac.ir \\ *** Corresponding author email: j.peighambardoust@ tabrizu.ac.ir
}

\section{Abstract}

One of the major environmental problems is the entry of colored pollutants into the oceans and seas. Adsorption is one of the effective methods to eliminate colorant polluting materials from wastewater streams. In this study, nanocomposite hydrogels of poly(methacrylic acid-co-acrylamide) (Poly(MAA-coAAm)) containing different weight percent bentonite clay nanoparticles $(0,5,10$, and 15 wt. \%) were used to remove methyl violet (MV) dye. FTIR, SEM, TGA, and XRD were used to analyze the properties of adsorbents. Results showed that bentonite nanoparticles were successfully distributed in the hydrogel system. Bentonite nanoparticles at $10 \mathrm{wt}$ \% gave the maximum MV dye adsorption efficiency. The highest adsorption was obtained at a $\mathrm{pH}$ of 5 , an adsorbent dosage of $1.5 \mathrm{~g} / \mathrm{L}$, a temperature of $25^{\circ} \mathrm{C}$, a contact time of $60 \mathrm{~min}$, and a pollutant concentration of $10 \mathrm{mg} / \mathrm{L}$. In thermodynamics studies, a negative values of Gibbs free energy $\left(\Delta \mathrm{G}^{\circ}\right)$ indicating that the adsorption process was spontaneous. In addition, Poly(MAA-coAAm) hydrogels and Poly(MAA-co-AAm)/bentonite nanocomposite hydrogels gave the adsorption enthalpy $\left(\Delta \mathrm{H}^{\circ}\right)$ of 22.2 and $47.4 \mathrm{KJ} / \mathrm{mol}$. Langmuir isotherm model was successfully applied in describing the equilibrium behavior of the adsorption process. To investigate the adsorption kinetics, we used pseudofirst-order, pseudo-second-order, and Elovich models. The kinetic study showed that the pseudo-secondorder model was more successful in describing the kinetic behavior of the adsorption process than pseudofirst-order and Elovich models. Incorporating bentonite clay nanoparticles in Poly(MAA-co-AAm) nanocomposite hydrogels significantly improved the adsorption and swelling efficiencies of these hydrogels. 
32 Keywords: Methacrylic acid-co-acrylamide copolymer, Nanocomposite hydrogel, Adsorption, Methyl

33 Violet

\section{Introduction}

Water pollution from the improper discharge of industrial dyes originated from various industries such as textile, leather, paper, plastic, tanning, etc. is a very serious environmental concern, which threaten the living organisms and ecosystem $[1,2]$. It is, therefore, necessary to remove these toxic pollutants from industrial effluents before discharging to the environment. Dyes are one of the most important groups of the pollutants $[3,4]$ and are usually classified into cationic (basic), anionic (direct, acidic, and reactive), and non-ionic [5,6] types. The annual production of industrial dyes is estimated to be 10,000 tons, of which about 1 to 10 percent of is being discharged to the environment [7]. Complete removal of dyes from the wastewater streams is a challenging issue because of their longer stability in the environment. In previous studies various techniques such as electrochemical, ion exchange, catalysis, deformation, adsorption and biological processes have been proposed to remove the dyes from aqueous solutions [8,9]. Water treatment systems based on hydrogel show the potential of efficient adsorption due to the three-dimensional network of polymer chains and hydrophilic nature of hydrogels [10]. In addition, hydrogels have the advantage of being cheap, non-toxic, chemically and physically stable, forming a good polymer network, and ability to recycle [11,12]. Hydrogels exhibit a high adsorption affinity to remove different chemicals from aqueous solutions even at lower concentrations, which makes them important for widespread use in environmental applications [13,14]. Common functional groups used in the synthesis of hydrogels include carboxylic acids, amides, amines, hydroxyl, and sulfonic acids. Highly adsorbable hydrogels swell due to the penetration of water at pre-existing or dynamically spaced distances between polymer chains [15]. In the structure of monomers, there is an acidic group - $\mathrm{COOH}$, which plays an important role in the adsorption and swelling properties of hydrogels. These monomers are present in the hydrogel structure in the form of copolymer bonds and frequently alter molecular chain experiences, hydrophobicity, response to stimuli, therapeutic behaviors, and the allowable amount of hydrogel [16]. Due to the presence of oxygen atoms, acrylics form complexes with metal cations and cationic dyes [17]. In addition, hydrogen bonds between polymer chains, water molecules and dyes are formed due to the presence of the $\mathrm{OH}$ group. Due to the weak acidity of the carboxylic group, the hydrogel behavior of acrylic 
patients is sensitive to $\mathrm{pH}$ [18]. In the adsorption process, various materials such as agricultural waste, natural polymers (chitin, chitosan, carboxy methylcellulose, etc.), silicate layers such as mineral clays and activated carbon may be used as adsorbents to remove certain chemicals from wastewaters [19]. Clay is a low-cost, biocompatible and abundant material with good mechanical and chemical properties, which can be used in the concept of wastewater treatment [20,21]. Bentonite nanoclay is one of the clay minerals that form Smectite family materials which is composed of two silica tetrahedral sheets with a central octahedral sheet and are designated as 2:1 layer mineral, and water molecules and cations occupying the space between the 2:1 layers. Bentonite is used to remove organic dyes due to its high surface area and cation-exchange ability $[22,23]$. The aim of this study was to synthesize and characterize Poly(MAA-co-AAm)/bentonite nanocomposite hydrogels as an effective adsorbent in the adsorption of methyl violet dye from aqueous solutions. FT-IR, SEM, TGA and XRD analyzes were used to describe the structure of the hydrogels. The effect of adsorption parameters such as temperature, contact time, dye concentration, adsorbent dosage and $\mathrm{pH}$ on the adsorption process efficiency was investigated. The Langmuir, Freundlich, Dubinin-Radushkevich (D-R) and Temkin isotherm models were used to describe the equilibrium behavior of adsorption process. Also, to study the kinetic behavior of the process, pseuso-first-order, pseudo-second-order and Elovich models were used. In addition, the thermodynamic behavior of traditional hydrogel samples was investigated.

\section{Materials and Methods}

\subsection{Materials}

Methacrylic acid (MAA) and acrylamide (AAm) monomers and methyl violet (MV) dye $\left(\lambda_{\max }=\right.$ $582 \mathrm{~nm}$ ) were purchased from Merck (Darmstadt, Germany). Potassium persulfate (KPS) was purchased from Samchun (Seoul, Korea). N,N'-Methylenebisacrylamide (MBA) and bentonite were purchased from Sigma Aldrich (Munich, Germany).

\subsection{Preparation of poly(MAA-co-AAm)/Bentonite nanocomposite hydrogels}

Free radical polymerization method was used to prepare poly(MAA-co-AAm) and poly(MAA-coAAm)/Bentonite nanocomposite hydrogels. For copolymerization of monomers in hydrogel synthesis, $5 \mathrm{ml}$ MAA were poured in a three-necked flask equipped with mechanical stirrer, nitrogen gas inlet-outlet and thermometer. The appropriate amount of bentonite (0-15 wt. \%) was 
dispersed in $2 \mathrm{~g}$ of AAm and $10 \mathrm{~mL}$ of deionized water, and the mixture was sonicated for $20 \mathrm{~min}$ at $25^{\circ} \mathrm{C}$ to disperse the nanoclay sheets in AAm solution. A mixture of bentonite, AAm and N,N'Methylenebisacrylamide (MBA) as a crosslinker were added to the three-neck flask and heated with MAA to $70^{\circ} \mathrm{C}$ during purification with nitrogen gas. After $30 \mathrm{~min}$, a potassium persulfate (KPS) as an initiator was added to the flask to produce free radicals. The gel was formed after 20 min and the reaction was continued for $3 \mathrm{~h}$ until the polymerization was completed. In order to remove the non-reactive monomers, the hydrogels were washed several times with deionized water (DW). The nanocomposite hydrogels were dried in an oven at $55^{\circ} \mathrm{C}$ for $48 \mathrm{~h}$. The dried hydrogels were grinded to 250-500 $\mu \mathrm{m}$ size and kept for further use. Poly(MAA-co-AAm) hydrogel, without bentonite nanaoclay, were synthesized according to the above method for comparison.

\subsection{Method of characterization}

The chemical structure of monomers (MAA and AAm), bentonite nanoclay, poly(MAA-co-AAm) and poly(MAA-co-AAm)/bentonite nanocomposite hydrogels were investigated by FTIR spectroscopy (Tensor 27, Broker, Germany). The scanning range of the samples was worked by IR spectra from wavenumbers from 400 to $4000 \mathrm{~cm}^{-1}$. X-ray diffraction patterns were obtained using an X-ray diffractometer (Siemens S5000, Germany) at $40 \mathrm{kV}$ and $30 \mathrm{~mA}$ equipped with a $\mathrm{CuKa}$ radiation source with a scanning speed of $0.2^{\circ}$ per minute at ambient temperature. To calculate the base distance $\left(\mathrm{d}_{001}\right)$ from the silicate layer, the Bragg equation $(\mathrm{n} \lambda=2 \mathrm{~d} \sin \theta)$ with

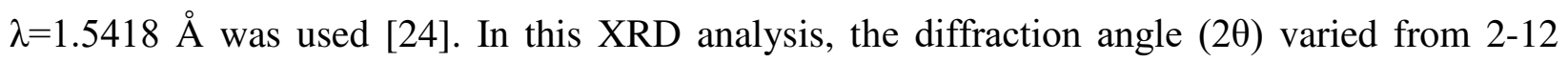
degrees. The morphology of the nanocomposite hydrogel surfaces was determined by scanning electron microscopy (SEM) analysis (FE-SEM MIRA3, FEG-SEM, TUSCAN, Czech Republic) equipped with X-ray scattering analysis (EDX). For SEM analysis, samples of poly(MAA-coAAm) and poly(MAA-co-AAm)/bentonite nanocomposite hydrogels were coated with a goldplated spray steam. To determine the nanoclay distribution at the cross-section of nanocomposite hydrogels, the main profiles in the sample thickness were obtained by EDXA and dot-mapping (Microanalysis Oxford Instruments model 7718 INCA PentaFET). Thermal stability of primary and nanocomposite hydrogel samples was performed by thermogravimetric analysis (TGA) using Linseis instrument (Linseis N81 A1750, USA) in the temperature range of $25-900^{\circ} \mathrm{C}$ with heating rate of $10^{\circ} \mathrm{C} /$ minute under nitrogen atmosphere [25]. 
120 To study the adsorption capacity, different concentrations of MV dye (10-100 mg/L) were 121 prepared for evaluation at different concentrations in DW. For this purpose, $0.05 \mathrm{~g}$ of dry hydrogel 122 was added to a $250 \mathrm{~mL}$ flask containing $50 \mathrm{~mL}$ of dye solution. Adsorption experiments were 123 performed on a magnetic stirrer at $800 \mathrm{rpm}$ at $25^{\circ} \mathrm{C}$ for $60 \mathrm{~min}$. After reaching equilibrium 124 absorption capacity (initial tests were performed at $25^{\circ} \mathrm{C}$, contact time of 60 min and weight of 1 $125 \mathrm{~g} / \mathrm{L}$ of the adsorbent dosage), the solutions were filtered by centrifugation and the amount of dye 126 adsorption was measured using the UV-Vis spectrophotometer (Agilent Technologies, model Cary 127 100, Santa Clara, CA, USA) at the maximum color emission wavelength. The adsorption capacity 128 of the adsorbents at equilibrium $\left(\mathrm{q}_{\mathrm{e}}, \mathrm{mg} / \mathrm{L}\right)$ and adsorption efficiency $(\mathrm{R} \%)$ were calculated using 129 Eqs. 1 and 2, respectively.

$\mathrm{R}(\%)=\frac{\left(\mathrm{C}_{0}-\mathrm{C}_{\mathrm{t}}\right)}{\mathrm{C}_{0}} \times 100$

$131 \quad \mathrm{q}_{\mathrm{t}}=\frac{\left(\mathrm{C}_{0}-\mathrm{C}_{\mathrm{t}}\right) \mathrm{V}}{\mathrm{m}}$

132 where, $\mathrm{C}_{0}$ is the initial concentration of the contaminant, $\mathrm{C}_{\mathrm{t}}$ is the final concentration, $\mathrm{V}$ is the 133 volume of the solution used, and $\mathrm{m}(\mathrm{g} / \mathrm{L})$ is amount of adsorbent used.

$134 \quad$ 2.5. Swelling behavior of hydrogels

135 Swelling behavior of copolymer and nanocomposite hydrogel samples were investigated. For this 136 purpose, $20 \mathrm{mg}$ of adsorbent was poured into $10 \mathrm{~mL}$ of $\mathrm{DW}$ and after one day (24 hours), the 137 solution was centrifuged. The adsorbent was separated from DW and weighed. The amount of 138 adsorbent swelling ratio was calculated using Eq. 3 [22].

139 Swelling Ratio $=\frac{\left(\mathrm{W}_{\text {wet }}-\mathrm{W}_{\mathrm{dry}}\right)}{\mathrm{W}_{\mathrm{dry}}}$

140 where, $\mathrm{W}_{\text {wet }}$ and $\mathrm{W}_{\text {dry }}$ are the weight of wet and dry hydrogel samples, respectively.

\section{3. Results and Discussion}

\section{$142 \quad 3.1$. Properties of hydrogels}


143 Fig. 1a shows the FTIR spectra of the bentonite nanoparticles, which indicating characteristic 144 peaks at wavenumber of $3616 \mathrm{~cm}^{-1}$ (corresponding to the tensile vibration of the hydrogen bonds), 1474 and $1596 \mathrm{~cm}^{-1}$ (indicating the bending of methylene groups) [26]. The rest of the vibrations are in the range of $1000-1050 \mathrm{~cm}^{-1}$ due to the tension of the Si-O-C bond [27]. Figure $1 \mathrm{~b}$ shows the FTIR spectra of poly(MAA-co-AAm) hydrogel after adsorption of the dye contaminant. The peaks at 1631 and $1699 \mathrm{~cm}^{-1}$ indicate the involvement of the carbonyl and vinyl groups of MAA monomer in the free radical polymerization. In addition, the peaks of 1728 and $1751 \mathrm{~cm}^{-1}$ are symmetrically bonded to carboxylate anions and $\mathrm{C}=\mathrm{O}$ tensile vibrations in the monomers, respectively [28]. Figure 1c shows the FTIR spectra of poly(MAA-co-AAm)/bentonite nanocomposites after adsorption of MV dye contaminants. Compared to the shape of the copolymer hydrogel, the vibration distance is reduced, which means that the methyl violet (MV) dye was trapped in the pores of the nanocomposite. In addition, the increase in the transmission spectrum in $1653 \mathrm{~cm}^{-1}$, which is related to the poly(MAA-co-AAm) bonds, indicates that these bonds are filled with dye contaminants. Finally, the peaks in the nanocomposite structure between $400-500 \mathrm{~cm}^{-1}$ are related to Si-O-Si and Si-O-Al bond tension [29].

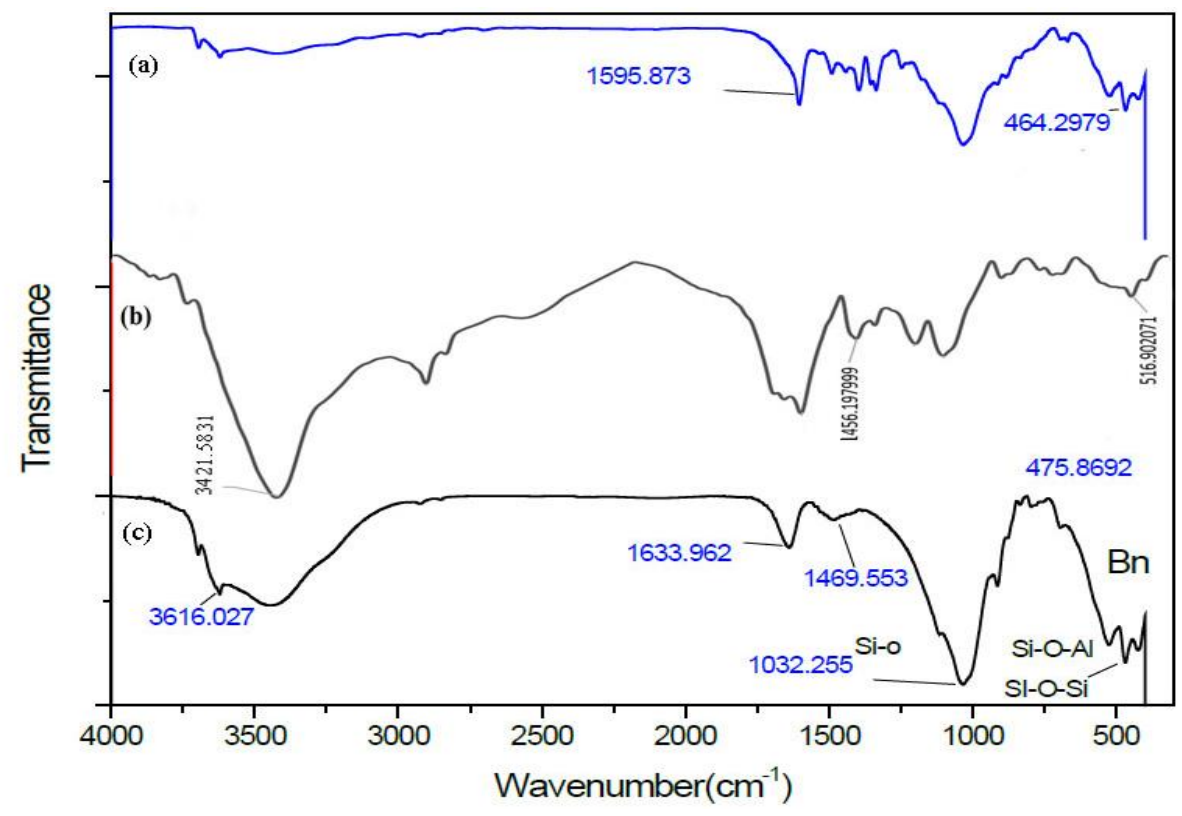

Fig. 1. FTIR results for a) bentonite b) poly(MAA-co-AAm) hydrogel c) poly(MAA-co-AAm)/bentonite nanocomposite hydrogel

162 poly(MAA-co-AAm)/bentonite nanocomposite hydrogels. As shown in the figure, bentonite 
nanoclay shows many diffraction peaks due to the presence of different crystalline phases. The distinct peak at $2 \theta=5-10^{\circ}$ (specified in $2 \theta=5.7^{\circ}$ ) related to the basal-spacing $\left(\mathrm{d}_{001}\right)$ for layered gallery structure of bentonite nanoclay. From Bragg's equation for layered silicates such as bentonite nanoclay, the d001 is calculated as $1.55 \mathrm{~nm}$. For poly(MAA-co-AAm) and poly(MAAco-AAm)/bentonite nanocomposite hydrogels, this distinct peak hasn't appeared which can be due to the complete disaggregation of the bentonite silicate layers during the formation of the nanocomposite structure. This means the complete dispersion of single layers of clay into polymeric matrix occurred. In this case, the exfoliated structure for the resulting nanocomposite is obtained. Also, in the poly(MAA-co-AAm)/bentonite nanocomposite hydrogel XRD pattern, some peaks in $2 \theta=12.5,16$, and $22^{\circ}$ are observed which indicating the lower crystalline structure of these samples [30].

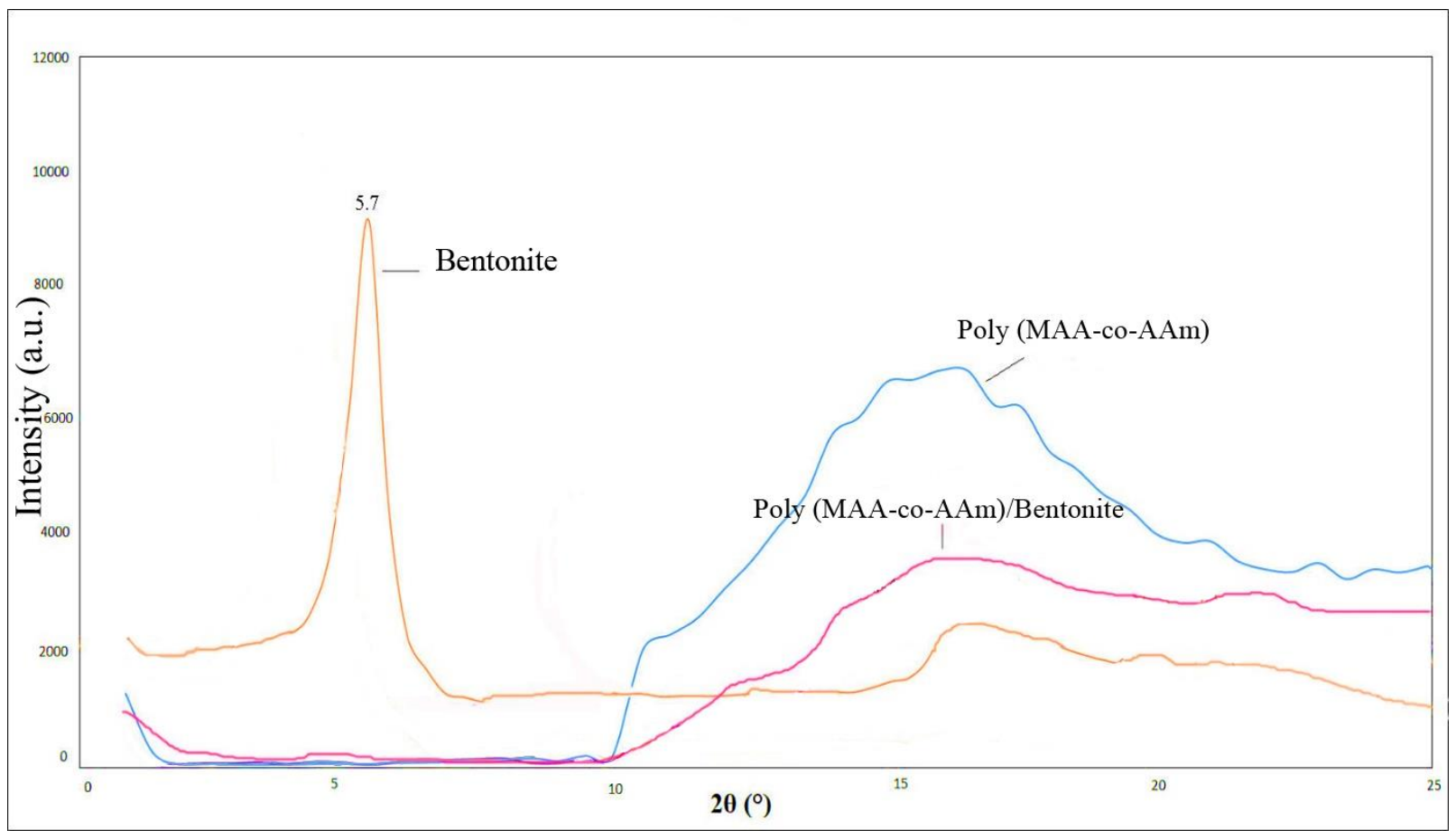

FFig. 2. X-ray diffraction results (XRD) of bentonite, poly(MAA-co-AAm), and poly(MAA-co$\mathrm{AAm}) /$ bentonite nanocomposites

Figure 3 shows the TGA curves of poly(MAA-co-AAm) and poly(MAA-co-AAm)/bentonite nanocomposite hydrogels. Usually, TGA analysis was performed to investigate the thermal stability behavior of poly(MAA-co-AAm) and poly(MAA-co-AAm)/bentonite nanocomposite hydrogels. The results of TGA analysis showed that the weight loss of copolymer and nanocomposite hydrogel samples was done in three stages. The first stage of weight loss occurred 
182 in the range of $50-150{ }^{\circ} \mathrm{C}$ temperature, which could be due to the evaporation of water content in 183 the samples. It is noteworthy that at this stage, the weight loss of the nanocomposite sample is more than the copolymer hydrogel sample and this is due to the presence of more water molecules in the structure of the nanocomposite hydrogel. The second stage of weight loss took place in the range of $200-450{ }^{\circ} \mathrm{C}$ temperature, where the hydrogels lost a significant part of their weight, which could be related to the destruction of acrylamide bonds as well as the decomposition of excellent monomer compounds. Also at this stage, the $\mathrm{C}-\mathrm{H}$ bond of methacrylic acid, which is the dominant monomer of the hydrogel, is decomposed. The final weight loss can be due to the decomposition and destruction of the structure of the mentioned materials, which at this stage we see a slight weight loss. As shown in Fig. 3, the addition of bentonite nanoparticles increases the thermal stability of the nanocomposite. In addition, a comparison of the nanocomposite sample with the sample without nanoclay shows that the addition of bentonite nanoclay to the polymeric hydrogel caused a significant increase in the temperature of the nanocomposite during the heating steps. This result may be due to the exfoliated structure that creates strong hydrogen bond interactions with methacrylic acid and acrylamide monomers, evaporating water molecules, destroying the chains and opening the nanocomposite layers.

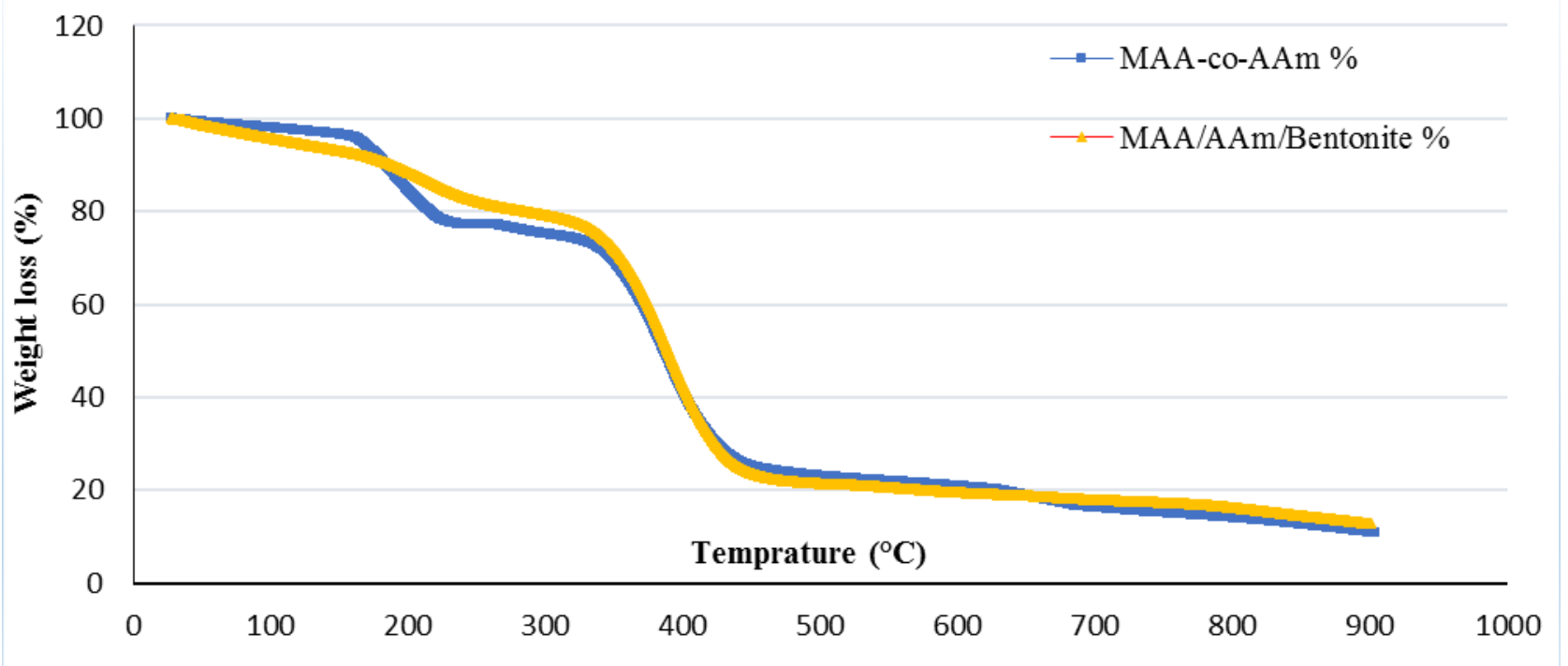

Fig. 3. Comparison of TGA analysis results of poly(MAA-co-AAm) and poly(MAA-co-AAm)/bentonite nanocomposite hydrogels 
In order to study morphology and changes in samples of poly(MAA-co-AAm) and poly(MAAco-AAm)/bentonite nanocomposite hydrogels before and after the methyl violet dye adsorption process, SEM-EDX and dot-mapping analysis were used. Fig. 4 shows the SEM micrographs for poly(MAA-co-AAm) and poly(MAA-co-AAm)/bentonite nanocomposite hydrogels in the dry state. In hydrogels, the amount of swelling depends on the porosity and the average size of the pores. Due to the presence of capillary forces, water is distributed through the pores. As shown in Figure $4 \mathrm{~b}$ the presence of bentonite nanoparticles increases the porosity of hydrogel and thus, increases the water permeability in the structure of hydrogels. Dot mapping of nanocomposite hydrogels was performed and the distribution of Si element as a marker of nanoparticles in purple dots is shown in Fig. 4c. Preliminary analysis of Si shows the cross-sectional distribution of clay nanoparticles on the nanocomposite hydrogel. As shown in Fig. 4a good distribution of nanoparticles is observed in nanocomposite hydrogel structures. This means that the clay nanoparticles were not accumulated in the hydrogel matrix. Also, after the methyl violet dye adsorption process, the pores and roughnesses on the surface of the composite used were almost saturated, which could be due to the penetration of dye molecules in these pores.

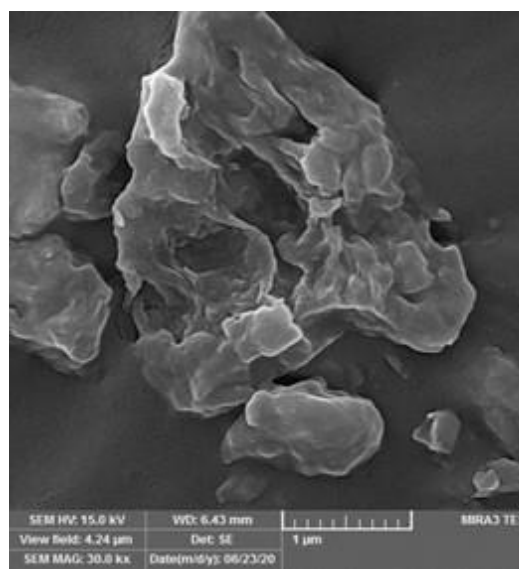

(a)

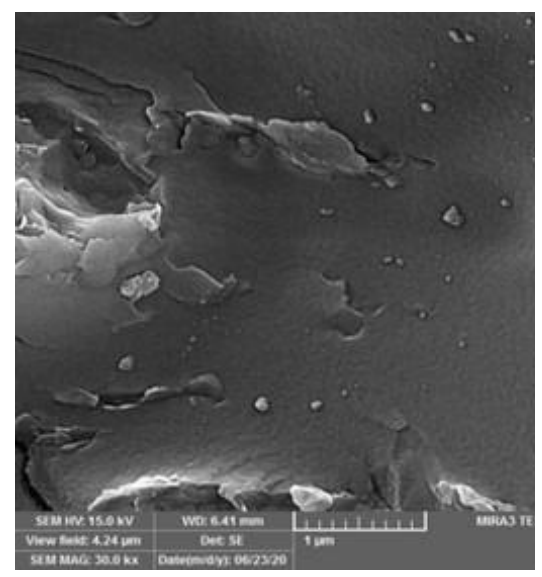

(b)

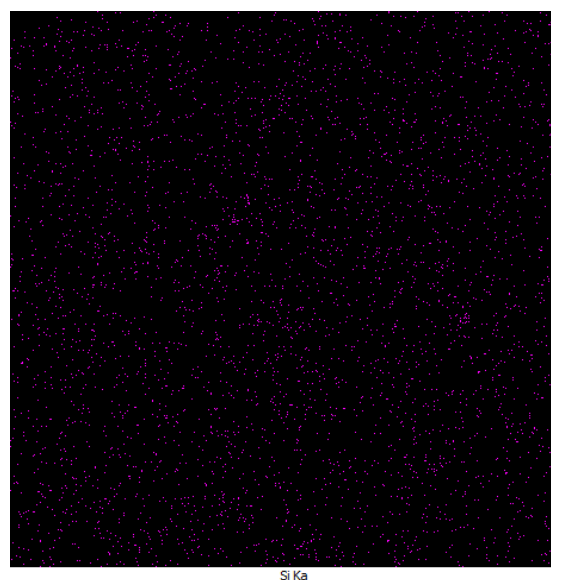

(c)

Figure 4. SEM images of a) poly(MAA-co-AAm) hydrogel, b) poly(MAA-co-AAm)/bentonite nanocomposite hydrogel, and c) dot-mapping of nanocomposite hydrogel

\subsection{The effect of different parameters on the adsorption performance}




\subsubsection{Weight concentration of nanoparticles}

222 Figure 5a shows effect of weight percent of nanoparticles on dye adsorption efficiency. A lower 223 dye adsorption was observed at either low (2.5 wt. \%) or high (15 wt. \%) of nanoparticles. A 224 highest dye adsorption of $96 \%$ was obtained at a nanoparticle weight percent range of 7.5-12.5. It

225 is known that with increasing the weight percentage of bentonite nanoparticles inside the hydrogel, 226 due to the increase of effective surface and active sites, the amount of dye adsorption increased 227 sharply and when the amount of bentonite nanoparticles reached to $12.5 \mathrm{wt}$. \%, due to the 228 accumulation of these nanoparticles inside the hydrogel, the dye adsorption decreases because in this weight percentage, the active sites available for the adsorption process are reduced.

230

231

232

233

234

235

236

237

238

239

240

241

242

243

244

245

246

247

248

249

\subsubsection{Initial $\mathbf{p H}$}

In the adsorption process, the initial $\mathrm{pH}$ is an important and effective parameter, because this parameter can affect adsorbent surface ionization and charge [32]. Figure 5b shows the effect of initial $\mathrm{pH}$ on dye adsorption efficiency for Poly(MAA-co-AAm) and Poly(MAA-co$\mathrm{AAm}$ )/bentonite nanocomposite hydrogels in the initial $\mathrm{pH}$ range of 3 to 10. First, the adsorption efficiency of Poly(MAA-co-AAm)/bentonite was higher than that of Poly(MAA-co-AAm) hydrogels at all $\mathrm{pH}$ ranges tested. Second, either at lower $(\mathrm{pH}<4)$ or higher $(\mathrm{pH}>9) \mathrm{pH}$ values, the adsorption efficiency was significantly reduced. A highest adsorption rate of 94 and $90 \%$ was obtained at $\mathrm{pH}=7$ for Poly(MAA-co-AAm)/bentonite and Poly(MAA-co-AAm) hydrogels, respectively. There are repulsive electrostatic forces between the adsorbent surface and the dye molecules originated from $\mathrm{H}^{+}$ions in acidic $\mathrm{pH}$, and $\mathrm{OH}^{-}$ions in alkaline $\mathrm{pH}$, which reduce the adsorption efficiency $[33,34]$.

\subsubsection{Adsorbent dose}

The adsorbent dose is another important parameter that affects the adsorption efficiency of contaminants [35]. In this study, the adsorption capacity of Poly(MAA-co-AAm) and Poly(MAAco-AAm)/bentonite nanocomposite hydrogels was evaluated at an adsorbent dose range of 0.5-4 $\mathrm{g} / \mathrm{L}$, an initial dye concentration of $10 \mathrm{mg} / \mathrm{L}$, an initial $\mathrm{pH}$ of 7, and a contact time of $60 \mathrm{~min}$. As can be seen from figure $5 \mathrm{c}$, the adsorption efficiency of Poly(MAA-co-AAm)/bentonite nanocomposite hydrogel was higher than that of Poly(MAA-co-AAm) hydrogel at all adsorbent dosages tested. By increasing the adsorbent dose, the adsorption efficiency for both hydrogel types 
250 is increased. This can be explained by an increased contact surface of the adsorbents, which 251 facilitates the adsorption process at a higher concentration. According to the results, with 252 increasing the adsorbent dose from 0.5 to $1.5 \mathrm{~g} / \mathrm{L}$, the adsorption efficiency of the dye was 253 increased. Dosage higher than $1.5 \mathrm{~g} / \mathrm{L}$ did not significantly change the adsorption efficiency of 254 both adsorbent types. This could be due to the reduction of dye concentration in aqueous solution 255 and reduction of active ingredient [36].

\section{3.2.4. The initial concentration of dye}

257 The initial concentration of pollutants in the adsorption process is one of the important factors

258 because it is regarded as a driving force to overcome the mass transfer resistance between solid 259 (adsorbent) phases and aqueous solutions [37]. Figure 5d demonstrates the effect of the initial 260 concentration of dye contaminants on the adsorption efficiency. Increasing the initial dye 261 concentration significantly decreased the adsorption efficiency for both types of adsorbents. At 262 low initial dye concentration, the intermolecular bonds of the dyes are low $(10 \mathrm{mg} / \mathrm{L})$, while at 263 high concentrations $(100 \mathrm{mg} / \mathrm{L})$ the active sites on the adsorbent surface are completely saturated 264 leaving extra dye molecules unabsorbed [38].

\subsubsection{Temperature}

266 Temperature is another effective parameter in the adsorption process because it changes the kinetic 267 energy of molecules, and therefore, affects the adsorption process [20]. To investigate the effect 268 of temperature on the adsorption efficiency, the temperature was changed in the range of $25-45^{\circ} \mathrm{C}$ 269 by a thermal heater and the results are shown in figure 5e. It can be seen from this figure that a 270 temperature of $25^{\circ} \mathrm{C}$ gave the highest adsorption rate (95\%). By increasing the temperature, the 271 mobility of the hydrogel side groups increases, causing the adsorbed dye molecules to separate 272 from the hydrogel structure and reduce the adsorption rate. This process indicates that the 273 adsorption reaction is exothermic. 


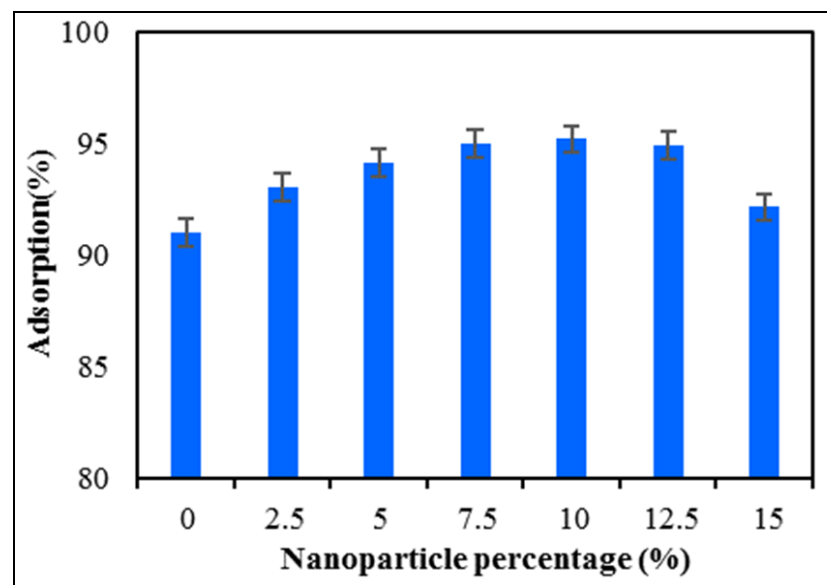

(a)

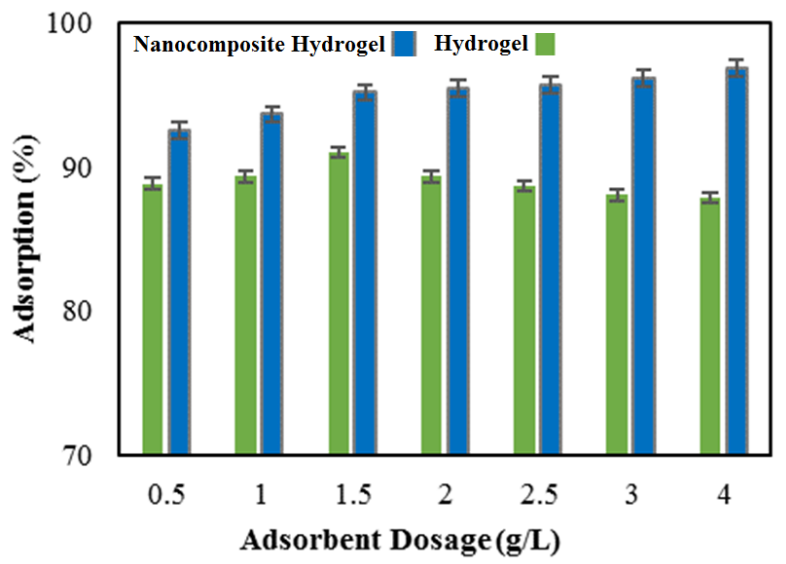

(c)

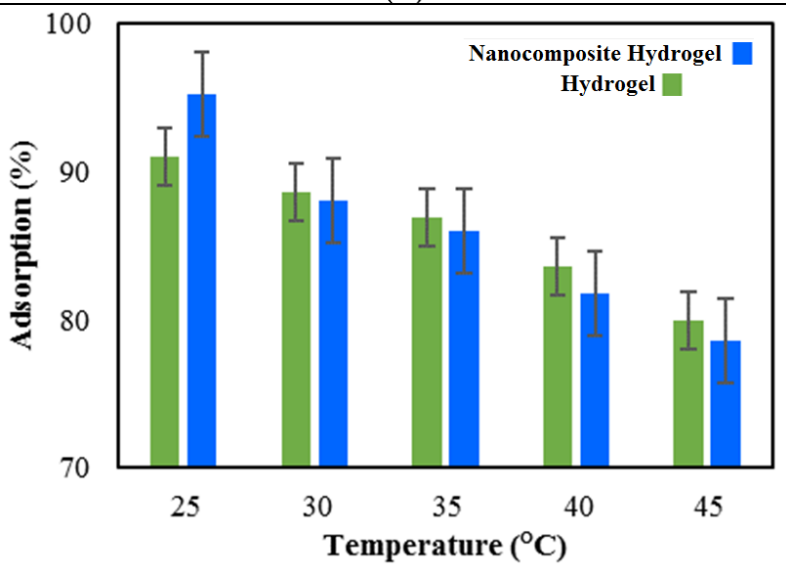

(e)

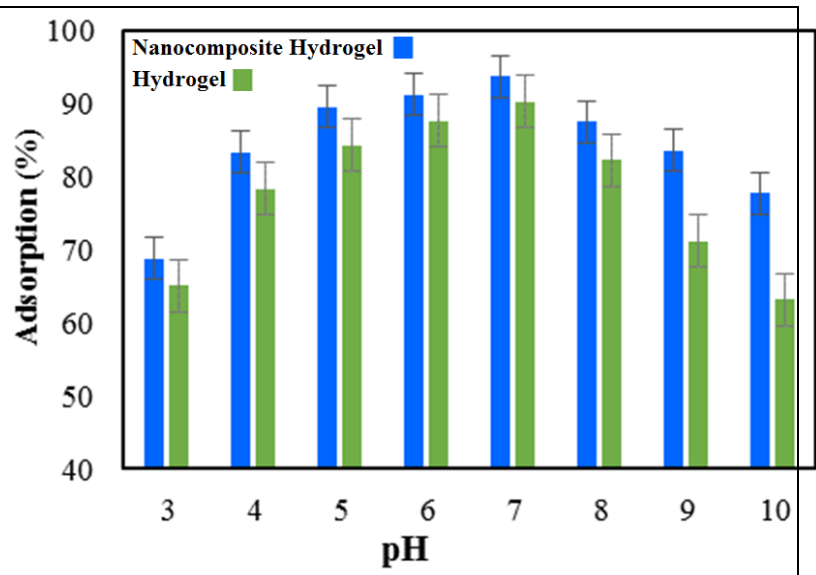

(b)

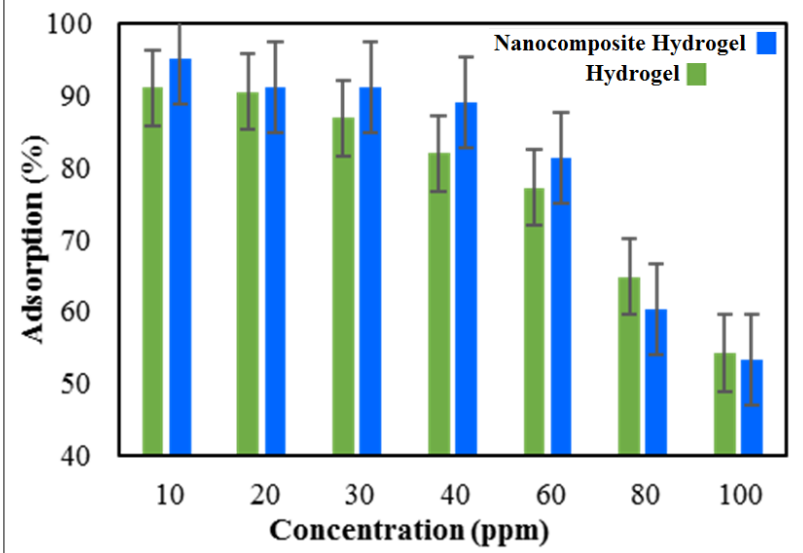

(d)

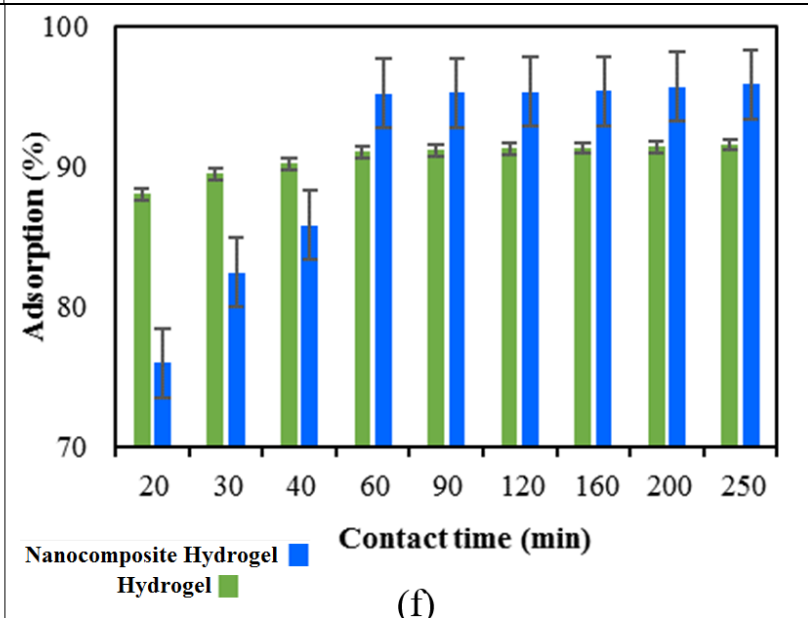

Figure 5. a) Effect of nanoparticle wt. \%, b) pH, c) adsorbent dosage, d) the initial concentration of dye (MV), e) contact time, and f) temperature on adsorption efficiency of poly(MAA-co-AAm) and poly(MAA-co$\mathrm{AAm}) / \mathrm{bentonite}$ nanocomposite hydrogels. Data are mean of triplicate measurements. Error bars indicate the standard deviation. 


\subsubsection{Contact time}

282 To evaluate the effect of contact time on the maximum adsorption efficiency of the dye, adsorption

283

284

285

286

287

288

289

290

291

292

293

294

295

296

297

298

299

300

301

302

303

304 at different time intervals (20-250 $\mathrm{min}), \mathrm{pH}=7$, adsorbent dose of $1.5 \mathrm{~g} / \mathrm{L}$ was performed. Figure 5f shows that the adsorption of dyes was faster in the early contact; however, the adsorption rate of the dye was almost constant after $60 \mathrm{~min}$. In the early contact time, there are unoccupied surfaces that are active to absorb the dye. When the contact time increases, the active sites on the adsorbent molecules become saturated decreasing the adsorption rate. According to the results, the optimal time for adsorption of dye contaminants with an initial concentration of $10 \mathrm{mg} / \mathrm{L}$ was obtained at $60 \mathrm{~min}$.

\subsection{Adsorption isotherm models}

Adsorption isotherm models are very important to determine the maximum adsorption capacity of dyes by adsorbents. In the present study, adsorption isotherm models of Langmuir, Freundlich, Dubinin-Radushkevich (D-R), and Temkin were used to evaluate the adsorption behavior of dye contaminants using two types of adsorbent hydrogels. The Langmuir [39], Freundlich [15], D-R [40], and Temkin [22] isotherm models can be expressed according to Eqs. 4, 5, 6, and 7, respectively.

$$
\text { Langmuir: } \quad \mathrm{q}_{\mathrm{e}}=\frac{\mathrm{q}_{\mathrm{m}} \cdot \mathrm{k}_{1} \cdot \mathrm{C}_{\mathrm{e}}}{1+\mathrm{k}_{1} \cdot \mathrm{C}_{\mathrm{e}}} \quad, \quad \mathrm{R}_{\mathrm{L}}=\frac{1}{1+\mathrm{K}_{\mathrm{L}}+\mathrm{C}_{\mathrm{e}}}
$$

Freundlich: $\quad \mathrm{q}_{\mathrm{e}}=\mathrm{k}_{\mathrm{f}} \mathrm{C}_{\mathrm{e}}^{1 / \mathrm{n}}$

$$
\text { D-R: } \quad \mathrm{q}_{\mathrm{e}}=\mathrm{q}_{\mathrm{m}} \cdot \exp \left(-\beta \varepsilon^{2}\right) \quad, \quad \varepsilon=\mathrm{RT} \operatorname{Ln}\left(1+\frac{1}{\mathrm{C}_{\mathrm{e}}}\right)
$$

$$
\text { Temkin: } \quad \mathrm{q}_{\mathrm{e}}=\mathrm{B} \operatorname{Ln}\left(\mathrm{A} \times \mathrm{C}_{\mathrm{e}}\right) \quad, \quad \mathrm{B}=\frac{\mathrm{RT}}{\mathrm{b}_{\mathrm{T}}}
$$

where $\mathrm{q}_{\mathrm{m}}$ is the maximum adsorption capacity of dye $(\mathrm{mg} / \mathrm{g}), \mathrm{K}_{\mathrm{L}}$ is the Langmuir constant, $\mathrm{K}_{\mathrm{F}}$ and $\mathrm{n}$ are the Freundlich constants, $\varepsilon$ is the Polanyi factor, $\beta$ reflects the activity coefficient $\left(\mathrm{mol}^{2} / \mathrm{J}^{2}\right), \mathrm{A}(1 / \mathrm{g})$ and $\mathrm{b}_{\mathrm{T}}(\mathrm{kJ} / \mathrm{mol})$ are Temkin constants, $\mathrm{R}$ is the global constant of gases, and $\mathrm{T}$ is the absolute temperature $(\mathrm{K})$. 
$305 \mathrm{k}_{\mathrm{L}}$ and $\mathrm{q}_{\mathrm{m}}$ can be obtained by tracking and tilting the $\mathrm{C}_{\mathrm{e}} / \mathrm{q}_{\mathrm{e}}$ diagram versus $\mathrm{C}_{\mathrm{e}}[39]$. The 306 dimensionless parameter $\mathrm{R}_{\mathrm{L}}$ is one of the important parameters of the Langmuir isotherm 307 model that determines the type of adsorption process. Accordingly, if the values of $R_{L}>1$, $308 \mathrm{R}_{\mathrm{L}}=1, \mathrm{R}_{\mathrm{L}}=0$ and $0<\mathrm{R}_{\mathrm{L}}<1$, the adsorption process is described as undesirable, linear, 309 irreversible and desirable, respectively. The value of the $R_{L}$ parameter for the MV dye 310 adsorption process was determined using both adsorbents used in the range 0-1, which 311 indicates that the adsorption process using both adsorbents is optimal [15]. By drawing a 312 linear isothermal shape, a constant can be obtained [22]. Figure 6 shows the nonlinear relationship 313 of isotherm models for the process of adsorption of MV dye from aqueous solution using 314 synthesized adsorbents, and the constants and parameters obtained are reported in Table 1. The 315 correlation coefficient $\left(\mathrm{R}^{2}\right)$ using the Langmuir isotherm model for the MV dye adsorption process 316 using the Poly(MAA-co-AAm) hydrogel and the Poly(MAA-co-AAm)/Bentonite nanocomposite 317 hydrogel were 0.9965 and 0.9986 , respectively. The amount of $\mathrm{R}^{2}$ determined using the Langmuir 318 isotherm model was higher than other models, indicating that homogeneous surfaces play an 319 important role in the MV dye adsorption process. Also, the value of parameter $\mathrm{n}$ for the MV dye 320 adsorption process using Poly(MAA-co-AAm) hydrogels and Poly(MAA-co-AAm)/Bentonite 321 nanocomposite hydrogels were 2.75 and 3.27, respectively, which confirms the optimal and 322 physical adsorption process. The values of $A_{T}$ and $b_{T}$ parameters that are determined using the 323 Temkin isotherm show that the interaction between the MV dye and the adsorbent surface has a 324 weak interaction. Therefore, the process of adsorption of MV dye using the desired adsorbents 325 may be physically present. Therefore, the process of adsorption of dye contaminants using the 326 desired adsorbents may be physically present. Parameter $\left(E=\frac{1}{\sqrt{2 \beta}}\right)$ was determined using the 327 D-R isotherm model below $8 \mathrm{KJ} / \mathrm{mol}$, which indicates that the process of adsorption of dye 328 contaminants is physically present [20]. 

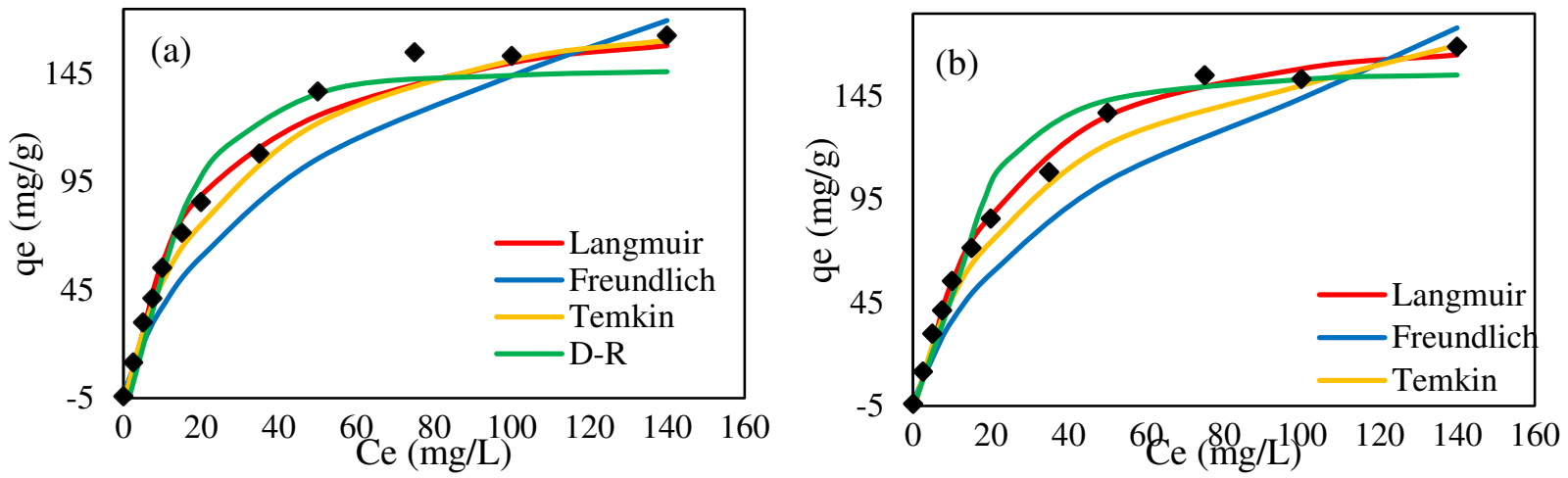

330 Figure 6. Linear relationship of Langmuir, Freundlich, Temkin, and D-R isotherm models for the adsorption MV dye from aqueous solution using Poly(MAA-co-AAm) hydrogel and Poly(MAA-co-AAm)/bentonite nanocomposite hydrogel.

333

Table 1. Equilibrium constants and parameters from adsorption process of MV dye

\begin{tabular}{|c|c|c|c|c|c|c|c|c|}
\hline \multirow[t]{2}{*}{ Hydrogel sample } & \multicolumn{2}{|r|}{ Langmuir } & \multicolumn{2}{|c|}{ Freundlich } & \multicolumn{2}{|c|}{ Temkin } & \multicolumn{2}{|c|}{$\begin{array}{c}\text { Dubinin- } \\
\text { Radushkevich (D-R) }\end{array}$} \\
\hline & $\mathrm{q}_{\mathrm{m}}$ & 137.037 & $\mathrm{n}$ & 2.75 & $\mathrm{~B}$ & 6.612 & $\mathrm{E}$ & 0.176 \\
\hline \multirow{4}{*}{ Poly(MAA-co-AAm) } & $\mathrm{k}$ & 0.201 & $\mathrm{k}$ & 10.69 & $\mathrm{~A}_{T}$ & 5.79 & $\mathrm{q}_{\mathrm{m}}$ & 150.45 \\
\hline & $\mathrm{R}_{\mathrm{L}}$ & $0.014-0.488$ & $\mathrm{R}^{2}$ & 0.8781 & $\mathrm{R}^{2}$ & 0.9351 & $\beta$ & $4 \times 10^{-6}$ \\
\hline & $\mathrm{R}^{2}$ & 0.9965 & & & & & $\mathrm{R}^{2}$ & 0.9214 \\
\hline & $\mathrm{q}_{\mathrm{m}}$ & 149.32 & $\mathrm{n}$ & 3.27 & $\mathrm{~B}$ & 8.077 & $\mathrm{E}$ & 0.372 \\
\hline Poly(MAA-co-AAm)/bentonite & $\mathrm{k}$ & 0.374 & $\mathrm{k}$ & 8.26 & $\mathrm{~A}_{\mathrm{T}}$ & 2.34 & $\mathrm{q}_{\mathrm{m}}$ & 174.11 \\
\hline \multirow[t]{2}{*}{ Nanaocomposite } & $\mathrm{R}_{\mathrm{L}}$ & $0.009-0.338$ & $\mathrm{R}^{2}$ & 0.9287 & $\mathrm{R}^{2}$ & 0.9844 & $\beta$ & $9 \times 10^{-7}$ \\
\hline & $\mathrm{R}^{2}$ & 0.9986 & & & & & $\mathrm{R}^{2}$ & 0.9398 \\
\hline
\end{tabular}

\subsection{Thermodynamics study}

337 To describe the thermodynamic behavior of the process of adsorption of dye pollutants 338 from aqueous solution using Poly(MAA-co-AAm) and Poly(MAA-co-AAm)/Bentonite 339 nanocomposite hydrogel from thermodynamic parameters enthalpy $\left(\Delta \mathrm{H}^{\circ}\right)$, entropy $\left(\Delta \mathrm{S}^{\circ}\right)$ 340 And Gibbs free energy $\left(\Delta \mathrm{G}^{\circ}\right)$ was used (Eqs. 8 and 9).

$$
\Delta \mathrm{G}=-\mathrm{R} \text { T Ln }\left(1000 \times \mathrm{K}_{\mathrm{D}}\right)
$$


343 where, $R$ is the universal constant of gases $(8.314 \mathrm{~J} / \mathrm{mol} . \mathrm{K}), \mathrm{T}$ is the absolute temperature $(\mathrm{K})$ and $344 \mathrm{~K}_{\mathrm{D}}\left(\mathrm{K}_{\mathrm{D}}=\mathrm{q}_{\mathrm{e}} / \mathrm{C}_{\mathrm{e}}\right)$ is the equilibrium constant.

345 To determine the values of $\Delta \mathrm{H}^{\circ}$ and $\Delta \mathrm{S}^{\circ}$, the slope and width of the $\ln \mathrm{K}_{\mathrm{D}}$ versus $1 / \mathrm{T}$ diagram 346 were used, respectively (Figure 7) and the calculated parameters are reported in Table 2. The value 347 of the parameter $\Delta \mathrm{G}^{\circ}$ for the adsorption of the dye pollutants was determined using both negative 348 adsorbents, indicating that the adsorption process is possible and spontaneous. The $\Delta \mathrm{H}$ values for 349 the adsorption process using Poly(MAA-co-AAm) and Poly(MAA-co-AAm)/bentonite 350 nanocomposite hydrogels were -61.24 and $-36.14 \mathrm{KJ} / \mathrm{mol}$, respectively. $\Delta \mathrm{H}^{\circ}$ negative indicates 351 that this process is exothermic in the temperature range $25-45^{\circ} \mathrm{C}$ using both adsorbents. The value 352 of the parameter $\Delta \mathrm{S}^{\mathrm{o}}$ was determined for the negative adsorption process, which shows that the 353 random collisions of dye pollutant molecules with the adsorbent surface increase during the 354 adsorption process $[20,41]$.

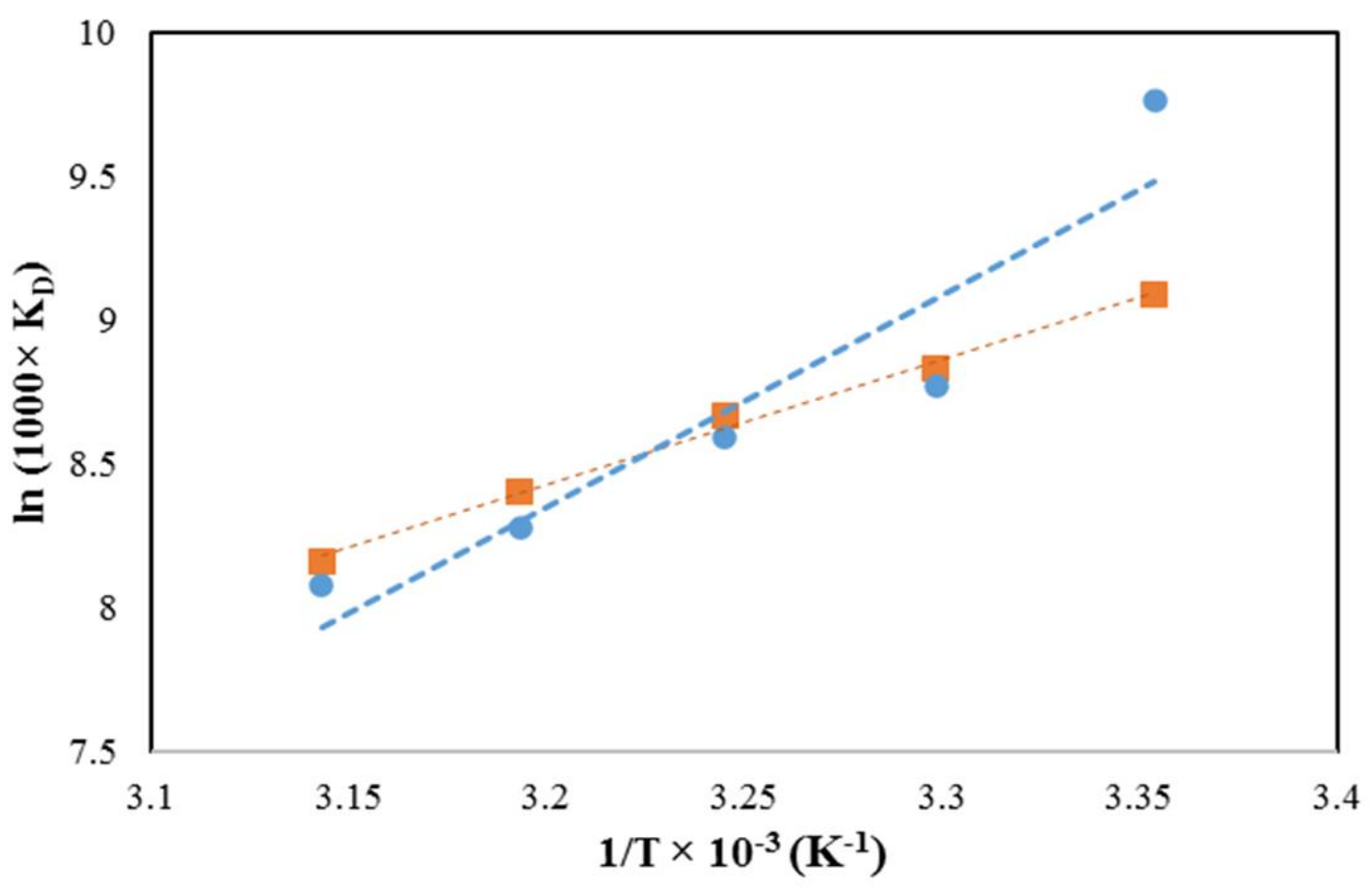


Table 2. Thermodynamic constants and parameters for the adsorption process of MV dye using Poly(MAA-co-

\begin{tabular}{|c|c|c|c|c|}
\hline Adsorbent) & $\mathbf{T}\left({ }^{\circ} \mathbf{C}\right)$ & $\Delta \mathbf{G}^{\circ}(\mathrm{KJ} / \mathrm{mol})$ & $\Delta \mathbf{H}^{\circ}(\mathrm{KJ} / \mathbf{m o l})$ & $\Delta \mathbf{S}^{\circ}(\mathbf{J} / \mathbf{m o l} . \mathbf{K})$ \\
\hline & 25 & -24.19 & & \\
\hline & 30 & -22.09 & & \\
\hline \multirow[t]{4}{*}{ Poly(MAA-co-AAm) Hydrogel } & 35 & -22.01 & -61.24 & -126.57 \\
\hline & 40 & -21.54 & & \\
\hline & 45 & -21.36 & & \\
\hline & 25 & -22.53 & & \\
\hline Poly(MAA-co-AAm)/bentonite & 30 & -22.25 & & \\
\hline \multirow[t]{3}{*}{ Nanocomposite Hydrogel } & 35 & -22.20 & -36.14 & -45.57 \\
\hline & 40 & -21.88 & & \\
\hline & 45 & -21.58 & & \\
\hline
\end{tabular}
AAm) hydrogel and Poly(MAA-co-AAm)/Bentonite nanocomposite hydrogel.

\subsection{Adsorption Kinetics Study}

Kinetic studies provide useful information about the mechanism of the adsorption process. In this study, pseudo-first-order kinetic models, pseudo-second-order, and Elovich kinematic models were used to analyze experimental data. The pseudo-first-order nonlinear model is as follows [41]:

$$
\mathrm{q}_{1}=\mathrm{q}_{\mathrm{e}}\left(1-\mathrm{e}^{-\mathrm{kt}}\right)
$$

and, the pseudo-second-order nonlinear model is as follows [42]:

$$
\mathrm{q}_{2}=\frac{\mathrm{K} \mathrm{q}_{\mathrm{e}}^{2} \mathrm{t}}{1+\mathrm{K} \mathrm{q}_{\mathrm{e}} \mathrm{t}}
$$

Also Elovich model is as follows [43]:

$$
\mathrm{q}_{2}=\frac{1}{\beta} \operatorname{Ln}(\alpha \beta \mathrm{t})
$$

where, $\mathrm{q}_{\mathrm{e}}$ and $\mathrm{q}_{\mathrm{t}}(\mathrm{mg} / \mathrm{g})$ show the absorption capacity of equilibrium and the absorption capacity at time $\mathrm{t}$, respectively. $\mathrm{k}_{1}\left(\mathrm{~min}^{-1}\right)$ and $\mathrm{k}_{2}(\mathrm{~g} / \mathrm{mg}$. $\mathrm{min})$ are the speed constants of the pseudo-firstorder and pseudo-second-order models, respectively. 
373 The slope and cut of the $\log$ diagram $\left(\mathrm{q}_{1 \mathrm{e}}-\mathrm{q}_{\mathrm{t}}\right)$ in front of $\mathrm{t}$ represent $\mathrm{k}_{1}$ and $\mathrm{q}_{1 \mathrm{e}}$. In the same way,

$374 \mathrm{k}_{2}$ and $\mathrm{q}_{2 \mathrm{e}}$ are calculated with graph $\mathrm{t} / \mathrm{q}_{\mathrm{t}}$ versus $\mathrm{t}$. Experimental data are analyzed using two kinetic

375

376

377

378

379

380

381

382

383

384

385

386

387

388

389

390

391

392

393 models and the parameters are calculated from the above equations and correlation coefficients are obtained. Eq.10 for the pseudo-first-order and Eq.11 for the pseudo-second-order were used to study the kinetics linearly. And the results are shown in Table 3. As can be seen from figure 8 and table 3 and the value of $\mathrm{R}^{2}$, the pseudo-second-order for Poly(MAA-co-AAm) and Poly(MAA-co$\mathrm{AAm}) /$ bentonite nanocomposite hydrogels have better and closer results to experimental results. Generally, the pseudo-second-order kinetic model has a correlation coefficient and adsorption compared to other models. Considering the values of $\mathrm{q}_{\mathrm{t} 2}$ and $\mathrm{k}_{2}$ parameters and matching the data with the pseudo-second-order kinetic model, the process of MV dye adsorption may be followed by a combined physical and chemical mechanism, but there is a basic chemical style. The $\alpha$ parameter values for the adsorption process of MV dye using Poly(MAA-co-AAm) hydrogel and Poly(MAA-co-AAm)/bentonite nanocomposite hydrogels were determined to be $0.4276 \mathrm{mg} / \mathrm{g} . \mathrm{min}$ and $22.15 \mathrm{mg} / \mathrm{g}$, respectively, this indicates that the composite produced has a high adsorption value.
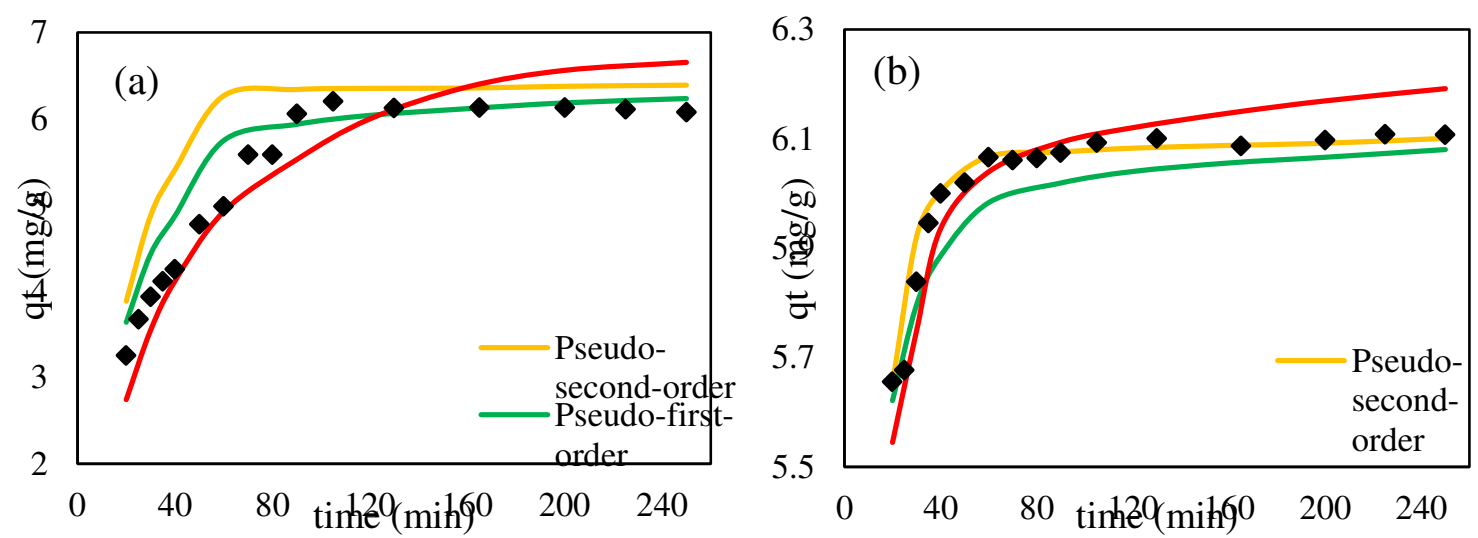

Figure 8. Nonlinear relationship of kinetic models to determine the kinetic parameters of the adsorption process MV dye using Poly(MAA-co-AAm) hydrogel and Poly(MAA-co-AAm)/bentonite nanocomposite hydrogels.

\section{Hydrogel sample}

Pseudo-first-order Model
Pseudo-second-order Model

Elovich Model 


\begin{tabular}{ccccccc}
\hline & $\mathrm{q}_{\mathrm{t}}$ & 5.33 & $\mathrm{q}_{\mathrm{t}}$ & 18.699 & $\alpha$ & 0.4276 \\
Poly(MAA-co-AAm) Hydrogel & $\mathrm{K}_{1}$ & 0.012 & $\mathrm{~K}_{2}$ & 0.341 & $\beta$ & 0.219 \\
& $\mathrm{R}^{2}$ & 0.925 & $\mathrm{R}^{2}$ & 0.932 & $\mathrm{R}^{2}$ & 0.876 \\
& & & & & & \\
Poly(MAA-co-AAm)/bentonite & $\mathrm{q}_{\mathrm{t}}$ & 6.069 & $\mathrm{q}_{\mathrm{t}}$ & 17.639 & $\alpha$ & 22.15 \\
Nanaocomposite Hydrogel & $\mathrm{K}_{1}$ & 0.165 & $\mathrm{~K}_{2}$ & 0.433 & $\beta$ & 0.436 \\
& $\mathrm{R}^{2}$ & 0.816 & $\mathrm{R}^{2}$ & 0.977 & $\mathrm{R}^{2}$ & 0.9042 \\
\hline
\end{tabular}

\section{Conclusions}

Dyes and pigments are the main pollutants in wastewater streams of various industries. FTIR analysis showed that amide and carboxylate groups are present in the structure of adsorbents that can play an important role in the process of MV dye adsorption. SEM analysis also showed that using MMT nanoparticles, the surface pores of the Poly(MAA-co-AAm) hydrogel system increased dramatically, which could be effective in absorbing MV dye. The Langmuir, Freundlich, D-R and, Temkin isotherm models were examined as equilibrium behaviors. The results showed that the the Langmuir model is more capable than other models. Single-layer adsorption capacity parameter values were determined using Langmuir model $\left(\mathrm{q}_{\max }\right)$ for Poly(MAA-co-AAm) and Poly(MAA-co-AAm)/bentonite nanocomposite hydrogels at 137.037 and $149.32 \mathrm{mg} / \mathrm{g}$, respectively. In addition, the parameters $n, R_{L}$ and, E determined using isothermal models showed that the MV dye adsorption process is physical and desirable. Also, the $\mathrm{A}_{\mathrm{T}}$ and $\mathrm{b}_{\mathrm{T}}$ values of the parameter determined using the Temkin isotherm showed that the interaction of the adsorbent surface with the MV dye molecule is weak and the adsorption process can be physical. The determined kinetic data have a good agreement with the quasi-second-order kinetic model and the quasi-second-order kinetic model has a higher correlation coefficient and absorption capacity than

412 quasi-second-order kinetics, the process of MV dye adsorption may be followed by a combined 413 physical-chemical mechanism. The thermodynamic parameters determined for the MV adsorption 414 process showed that the adsorption process is spontaneous and exothermic and the interaction of 415 the adsorbent surface with MV dye increases in the temperature range of $25-45^{\circ} \mathrm{C}$.

\section{References}


417 1. Mittal, H.; Babu, R.; Alhassan, S.M. Utilization of gum xanthan based superporous hydrogels for 418 the effective removal of methyl violet from aqueous solution. Int. J. Biol. Macromol. 2020, 143, 413-423.

420

421

422

423

424

425

426

427

428

429

430

431

432

433

434

435

436

437

438

439

440

441

442

443

444

445

446

2. Wadhera, P.; Jindal, R.; Dogra, R. Synthesis of semi interpenetrating network hydrogel [(GrA-Psy)cl-Poly (AA)] and its application for efficient removal of malachite green from aqueous solution. Polym. Eng. Sci. 2019, 59, 1416-1427.

3. Eskhan, A.; Banat, F.; Selvaraj, M.; Abu Haija, M. Enhanced removal of methyl violet 6B cationic dye from aqueous solutions using calcium alginate hydrogel grafted with poly (styrene-co-maleic anhydride). Polym. Bull. 2019, 76, 175-203, doi:10.1007/s00289-018-2378-y.

4. Beyranvand, N.S.; Samiey, B.; Tehrani, A.D.; Soleimani, K. Graphene oxide-cellulose nanowhisker hydrogel nanocomposite as a novel adsorbent for methylene blue. J. Chem. Eng. Data 2019, 64, $5558-5570$.

5. Sharma, G.; Kumar, A.; Sharma, S.; Ala'a, H.; Naushad, M.; Ghfar, A.A.; Ahamad, T.; Stadler, F.J. Fabrication and characterization of novel Fe0@ Guar gum-crosslinked-soya lecithin nanocomposite hydrogel for photocatalytic degradation of methyl violet dye. Sep. Purif. Technol. 2019, 211, 895908.

6. Gadisa, B.T.; Appiah-Ntiamoah, R.; Kim, H. Amorphous iron sulfide nanowires as an efficient adsorbent for toxic dye effluents remediation. Environ. Sci. Pollut. Res. 2019, 26, 2734-2746.

7. Foroutan, R.; Mohammadi, R.; Ramavandi, B. Elimination performance of methylene blue, methyl violet, and Nile blue from aqueous media using $\mathrm{AC} / \mathrm{CoFe}_{2} \mathrm{O}_{4}$ as a recyclable magnetic composite. Environ. Sci. Pollut. Res. 2019, 26, 19523-19539.

8. Mallakpour, S.; Tabesh, F. Tragacanth gum based hydrogel nanocomposites for the adsorption of methylene blue: Comparison of linear and non-linear forms of different adsorption isotherm and kinetics models. Int. J. Biol. Macromol. 2019, 133, 754-766.

9. Mittal, H.; Morajkar, P.P.; Al Alili, A.; Alhassan, S.M. In-situ synthesis of ZnO nanoparticles using gum arabic based hydrogels as a self-template for effective malachite green dye adsorption. $J$. Polym. Environ. 2020, 28, 1637-1653.

10. Thakur, S.; Verma, A.; Sharma, B.; Chaudhary, J.; Tamulevicius, S.; Thakur, V.K. Recent developments in recycling of polystyrene based plastics. Curr. Opin. Green Sustain. Chem. 2018, 13, 32-38. 
11. Kaur, K.; Jindal, R. Comparative study on the behaviour of Chitosan-Gelatin based Hydrogel and nanocomposite ion exchanger synthesized under microwave conditions towards photocatalytic removal of cationic dyes. Carbohydr. Polym. 2019, 207, 398-410.

12. Verma, A.; Thakur, S.; Mamba, G.; Gupta, R.K.; Thakur, P.; Thakur, V.K. Graphite modified sodium alginate hydrogel composite for efficient removal of malachite green dye. Int. J. Biol. Macromol. 2020, 148, 1130-1139.

13. Rabipour, M.; Pour, Z.S.; Sahraei, R.; Ghaemy, M.; Jazi, M.E.; Mlsna, T.E. pH-Sensitive Nanocomposite Hydrogels Based on Poly (Vinyl Alcohol) Macromonomer and Graphene Oxide for Removal of Cationic Dyes from Aqueous Solutions. J. Polym. Environ. 2020, 28, 584-597.

14. Al-Aidy, H.; Amdeha, E. Green adsorbents based on polyacrylic acid-acrylamide grafted starch hydrogels: the new approach for enhanced adsorption of malachite green dye from aqueous solution. Int. J. Environ. Anal. Chem. 2020, 1-21.

15. Pakdel, P.M.; Peighambardoust, S.J. Review on recent progress in chitosan-based hydrogels for wastewater treatment application. Carbohydr. Polym. 2018, 201, 264-279.

16. Sharma, K.; Kumar, V.; Kaith, B.S.; Kumar, V.; Som, S.; Kalia, S.; Swart, H.C. Synthesis, characterization and water retention study of biodegradable Gum ghatti-poly (acrylic acid-aniline) hydrogels. Polym. Degrad. Stab. 2015, 111, 20-31.

17. Yetimoğlu, E.K.; Kahraman, M. V; Ercan, Ö.; Akdemir, Z.S.; Apohan, N.K. Nvinylpyrrolidone/acrylic acid/2-acrylamido-2-methylpropane sulfonic acid based hydrogels: synthesis, characterization and their application in the removal of heavy metals. React. Funct. Polym. 2007, 67, 451-460.

18. Pakdel, P.M.; Peighambardoust, S.J. A review on acrylic based hydrogels and their applications in wastewater treatment. J. Environ. Manage. 2018, 217, 123-143.

19. Foroutan, R.; Peighambardoust, S.J.; Peighambardoust, S.H.; Pateiro, M.; Lorenzo, J.M. Adsorption of Crystal Violet Dye Using Activated Carbon of Lemon Wood and Activated Carbon/ $/ \mathrm{Fe}_{3} \mathrm{O}_{4}$ Magnetic Nanocomposite from Aqueous Solutions: A Kinetic, Equilibrium and Thermodynamic Study. Mol. 2021, 26.

20. Peighambardoust, S.J.; Aghamohammadi-Bavil, O.; Foroutan, R.; Arsalani, N. Removal of malachite green using carboxymethyl cellulose-g-polyacrylamide/montmorillonite nanocomposite hydrogel. Int. J. Biol. Macromol. 2020, 159, 1122-1131, 
doi:https://doi.org/10.1016/j.ijbiomac.2020.05.093.

478 21. Moharrami, P.; Motamedi, E. Application of cellulose nanocrystals prepared from agricultural wastes for synthesis of starch-based hydrogel nanocomposites: Efficient and selective nanoadsorbent for removal of cationic dyes from water. Bioresour. Technol. 2020, 313, 123661.

22. Abdolhosseinzadeh, M.; Peighambardoust, S.J.; Erfan-Niya, H.; Pakdel, P.M. Swelling and auramine-O adsorption of carboxymethyl cellulose grafted poly (methyl methacrylate)/Cloisite 30B nanocomposite hydrogels. Iran. Polym. J. 2018, 27, 807-818.

23. da Silva, R.C.; de Aguiar, S.B.; da Cunha, P.L.R.; de Paula, R.C.M.; Feitosa, J.P.A. Effect of microwave on the synthesis of polyacrylamide-g-chitosan gel for azo dye removal. React. Funct. Polym. 2020, 148, 104491.

24. Wang, G.; Shen, J.; Liu, S.; Jiang, C.; Qin, X. Three-dimensional modeling and analysis of macro488 pore structure of coal using combined X-ray CT imaging and fractal theory. Int. J. Rock Mech. Min. Sci. 2019, 123, 104082.

25. Nzioka, A.M.; Kim, M.-G.; Hwang, H.-U.; Kim, Y.-J. Kinetic study of the thermal decomposition process of municipal solid waste using TGA. Waste and Biomass Valorization 2019, 10, 1679-1691.

26. Ibrahim, W.M.; Hassan, A.F.; Azab, Y.A. Biosorption of toxic heavy metals from aqueous solution by Ulva lactuca activated carbon. Egypt. J. basic Appl. Sci. 2016, 3, 241-249.

27. Chrzanowska, E.; Gierszewska, M.; Kujawa, J.; Raszkowska-Kaczor, A.; Kujawski, W. Development and characterization of polyamide-supported chitosan nanocomposite membranes for hydrophilic pervaporation. Polymers (Basel). 2018, 10, 868.

28. Khan, S.A.; Siddiqui, M.F.; Khan, T.A. Synthesis of poly (methacrylic acid)/montmorillonite hydrogel nanocomposite for efficient adsorption of amoxicillin and diclofenac from aqueous Environment: kinetic, isotherm, reusability, and thermodynamic investigations. ACS omega $\mathbf{2 0 2 0}$, $5,2843-2855$.

29. Youssef, A.M.; Al-Awadhi, M.M.; Akl, M.A. Solid phase extraction and spectrophotometric determination of methylene blue in environmental samples using bentonite and acid activated bentonite from Egypt. J. Anal. Bioanal. Tech. 2014, 5, 1.

30. P. Taylor, "Particulate Science and Technology : An Use of FTIR Spectroscopy in the Characterization of Natural and Treated Nanostructured Bentonites ( Montmorillonites ) Use of FTIR Spectroscopy in the Characterization of Natural and Treated Nanostructured Bentonites," no. 
September 2014, pp. 37-41, 2012.

508

509

510

511

512

513

514

515

516

517

518

519

520

521

522

523

524

525

526

527

528

529

530

531

532

533

534

535

536

31. Koosha, M.; Hamedi, S. Intelligent Chitosan/PVA nanocomposite films containing black carrot anthocyanin and bentonite nanoclays with improved mechanical, thermal and antibacterial properties. Prog. Org. Coatings 2019, 127, 338-347.

32. David, M.K.; Okoro, U.C.; Akpomie, K.G.; Okey, C.; Oluwasola, H.O. Thermal and hydrothermal alkaline modification of kaolin for the adsorptive removal of lead (II) ions from aqueous solution. SN Appl. Sci. 2020, 2, 1-13.

33. Forutan, R.; Ehsandoost, E.; Hadipour, S.; Mobaraki, Z.; Saleki, M.; Mohebbi, G. Kinetic and equilibrium studies on the adsorption of lead by the chitin of pink shrimp (Solenocera melantho). Entomol. Appl. Sci. Lett 2016, 3, 20-26.

34. Rahimi, K.; Mirzaei, R.; Akbari, A.; Mirghaffari, N. Preparation of nanoparticle-modified polymeric adsorbent using wastage fuzzes of mechanized carpet and its application in dye removal from aqueous solution. J. Clean. Prod. 2018, 178, 373-383.

35. Atangana, E. Adsorption of $\mathrm{Zn}$ (II) and $\mathrm{Pb}$ (II) ions from aqueous solution using chitosan crosslinked formaldehyde adsorbent to protect the environment. J. Polym. Environ. 2019, 27, 2281-2291.

36. García, F.E.; Plaza-Cazón, J.; Montesinos, V.N.; Donati, E.R.; Litter, M.I. Combined strategy for removal of Reactive Black 5 by biomass sorption on Macrocystis pyrifera and zerovalent iron nanoparticles. J. Environ. Manage. 2018, 207, 70-79.

37. Hajizadeh, H.; Peighambardoust, S.J.; Peighambardoust, S.H.; Peressini, D. Physical, mechanical and antibacterial characteristics of bio-nanocomposite films loaded with Ag-modified $\mathrm{SiO}_{2}$ and $\mathrm{TiO}_{2}$ nanoparticles. J. Food Sci. 2020, 85, 1193-1202.

38. Agnihotri, S.; Singhal, R. Effect of sodium alginate content in acrylic acid/sodium humate/sodium alginate superabsorbent hydrogel on removal capacity of MB and CV dye by adsorption. J. Polym. Environ. 2019, 27, 372-385.

39. Ahmadi, A.; Foroutan, R.; Esmaeili, H.; Tamjidi, S. The role of bentonite clay and bentonite clay@ $\mathrm{MnFe}_{2} \mathrm{O}_{4}$ composite and their physico-chemical properties on the removal of $\mathrm{Cr}(\mathrm{III})$ and Cr(VI) from aqueous media. Environ. Sci. Pollut. Res. 2020, 27, 14044-14057, doi:10.1007/s11356020-07756-x.

40. Shafiee, M.; Foroutan, R.; Fouladi, K.; Ahmadlouydarab, M.; Ramavandi, B.; Sahebi, S. Application of oak powder $/ \mathrm{Fe}_{3} \mathrm{O}_{4}$ magnetic composite in toxic metals removal from aqueous solutions. $A d v$. 
Powder Technol. 2019, 30, 544-554, doi:https://doi.org/10.1016/j.apt.2018.12.006.

538

539

540

541

542

543

544

545

41. Sabbagh, F.; Khatir, N.M.; Karim, A.K.; Nazari, Z.; Jaberi, R. Mechanical Properties and Swelling Behav- ior of Acrylamide Hydrogels using Mont- morillonite and Kaolinite as Clays. 2019, 7, 211219.

42. Sar1, A.; Tuzen, M. Equilibrium, thermodynamic and kinetic studies on aluminum biosorption from aqueous solution by brown algae (Padina pavonica) biomass. J. Hazard. Mater. 2009, 171, 973979.

43. Largitte, L.; Pasquier, R. A review of the kinetics adsorption models and their application to the adsorption of lead by an activated carbon. Chem. Eng. Res. Des. 2016, 109, 495-504. 